\title{
Impacts of phototherapy on DNA damage and total oxidant/ antioxidant status in jaundiced newborns
}

\author{
Özgül Bulut ${ }^{1}$, Saadettin Dürüyen ${ }^{2}$ \\ ${ }^{1}$ Division of Neonatology, Department of Pediatrics and ${ }^{2}$ Department of Biochemistry, Istanbul Medeniyet University \\ Göztepe Training and Research Hospital, İstanbul, Turkey. E-mail: ozgulbulut@yahoo.com \\ Received: 28th January 2019, Accepted: 20th March 2019
}

SUMMARY: Bulut Ö, Dürüyen S. Impacts of phototherapy on DNA damage and total oxidant/antioxidant status in jaundiced newborns. Turk J Pediatr 2019; 61: 697-703.

Jaundice is common in newborn babies, and pathologic hyperbilirubinemia is frequently treated with phototherapy. Although it is considered to be safe, the side effects of phototherapy in newborns are still a matter of debate. In this study, the impacts of two types of phototherapy, conventional fluorescence and intensive light-emitting diodes (LED), on DNA damage and total oxidant/ antioxidant status in jaundiced newborns were assessed. The study group included 40 newborns (gestation age $\geq 37$ weeks) on days 2-8 after birth. Newborns were divided into two groups on the basis of need for phototherapy: 20 newborns were exposed to conventional phototherapy (Group I); and 20 infants were exposed to intensive phototherapy (Group II). Blood samples were taken from all infants at admission and after phototherapy to determine plasma 8-hydroxy-2-deoxy-guanosine (8-OH-dG; a marker of DNA damage), total oxidant status (TOS), and total antioxidant capacity (TAC). The oxidative stress index (OSI) was also calculated. Demographic information was recorded, and DNA damage, TOS, and TAC were compared. There were no differences in demographic information between the two groups. There were no significant differences in DNA damage, TOS, TAC, and OSI between Groups I and II before phototherapy $(p>0.05)$ and no significant differences in DNA damage, TOS, TAC, and OSI between the two groups after phototherapy $(p>0.05)$. However, the TAC decreased significantly in both groups after phototherapy $(p<0.01)$. These findings suggest that conventional and intensive phototherapies do not affect DNA damage and oxidative stress, supporting the safety of its use as the preferred treatment for jaundiced newborns.

Key words: DNA damage, oxidative stress, phototherapy, newborn.

Neonatal jaundice is very common in newborns. ${ }^{1}$ In the majority of cases, total bilirubin (TB) levels do not exceed the physiological limit. However, TB levels may rise, rarely, to very high levels and cause kernicterus, ${ }^{2}$ necessitating a rapid intervention strategy. Phototherapy is the most widely used therapy for management of neonatal jaundice. ${ }^{3}$ Phototherapy uses light energy to change the molecular structure of bilirubin. The resultant products are less lipophilic than bilirubin, and can be excreted in bile or urine without conjugation. ${ }^{4,5}$ Bilirubin absorbs light most strongly in the blue region of the spectrum near $460 \mathrm{~nm}$, and the effectiveness of phototherapy is dependent on the intensity and wavelength of light used. Several phototherapy devices are available, which use light sources with different wavelengths and densities. ${ }^{6}$ Current phototherapy systems use conventional compact fluorescent lamps or light-emitting diodes (LEDs), of which LEDs generate significantly higher light irradiance levels. ${ }^{7}$

Phototherapy is generally considered a safe and well-tolerated therapy in neonatal jaundice. ${ }^{8}$ However, some reports have indicated that phototherapy may cause oxidative stress, lipid peroxidation, and DNA damage. ${ }^{9-15}$ 
Moreover, neonates have a limited antioxidant protective capacity, and oxidative damage has an important role in the pathogenesis of many diseases in the newborn period. ${ }^{16}$

Therefore, this study aimed to assess the impacts of conventional and LED phototherapy on DNA damage, total oxidant status (TOS), and total antioxidant capacity (TAC) in jaundiced newborns.

\section{Material and Methods}

The study was approved by the local Research Ethics Committee (The report number \#: 2015/0010). Written informed consent was obtained from all parents before inclusion.

\section{Patients}

The study group included 40 newborns (gestation age $\geq 37$ weeks) on days $2-8$ after birth who had idiopathic unconjugated hyperbilirubinemia with TB levels above the threshold for the requirement of phototherapy in the first week life, as defined by the hourspecific bilirubin nomogram of the American Academy of Pediatrics. ${ }^{17}$ Demographic characteristics, obtained before the trial commenced, were recorded for each infant. The exclusion criteria were neonates with $\mathrm{ABO} / \mathrm{Rh}$ incompatibility, a positive direct Coombs test, glucose 6-phosphate dehydrogenase deficiency, perinatal asphyxia, systemic or metabolic disorders, shock, sepsis, hypoalbuminemia (serum albumin $<3.0 \mathrm{~g} / \mathrm{dL}$ ), findings of bilirubin encephalopathy at presentation (i.e., head extension, crying, hypotonia, or hypertonia), congenital hypothyroidism, or any other malformation. Patients were assigned to the two groups on the basis of the need for phototherapy, and the type of phototherapy applied was randomly assigned by the neonatal staff. Group I comprised 20 infants exposed to conventional phototherapy, and Group II comprised 20 infants exposed to LED phototherapy.

\section{Phototherapy}

In Group I, phototherapy was applied using an AMS Phototherapy System (AMS Trading, Dhaka, Bangladesh; intensity: 12-16 $\mu \mathrm{W} /$ $\mathrm{cm}^{2} / \mathrm{nm}$, spectrum $430-470 \mathrm{~nm}$, consisting of six fluorescent lamps). In Group II, phototherapy was applied using a Babyblue LED phototherapy system (TENDE, Ankara, Turkey; intensity: $90-120 \mu \mathrm{W} / \mathrm{cm}^{2} / \mathrm{nm}$, spectrum $450-460 \mathrm{~nm}$ ). The respective system was positioned over each infant at a distance of $40 \mathrm{~cm}$. Neonates were exposed completely, except for eyes and genitalia. Continuous phototherapy was calculated in hours, and minimally interrupted for feeding and cleaning. The infants' weight and temperature were closely monitored during phototherapy. Phototherapy was stopped when serum TB levels were below $2 \mathrm{mg} / \mathrm{dL}$, representing the lower limit for phototherapy. Infants were carefully monitored for possible side effects of phototherapy, including dehydration, hypothermia, hyperthermia, skin rash, and diarrhea.

\section{Blood sampling}

Venous blood samples $\left(2 \mathrm{~cm}^{3}\right)$ were drawn from all newborns before phototherapy for the measurement of TB, plasma 8-hydroxy2-deoxy-guanosine (8-OH-dG; a marker of DNA damage), TOS, and TAC. Serum TB levels were measured immediately, whereas samples for 8-OH-dG, TOS, and TAC were centrifugated at $1500 \times g$ for 10 min within 30 min of collection, and stored at $-80^{\circ} \mathrm{C}$ until analysis. Second blood samples $\left(2 \mathrm{~cm}^{3}\right)$ for measurement of TB, 8-OH-dG, TOS, and TAC were taken from a peripheral vein following phototherapy. Samples were centrifugated at $1500 \times \mathrm{g}$ for $10 \mathrm{~min}$ within $30 \mathrm{~min}$ of collection, and stored at $-80^{\circ} \mathrm{C}$ until analysis.

\section{Analysis of DNA damage}

DNA damage was assessed using 8-OH-dG concentrations, which were measured using a commercially available enzyme-linked immunoassay kit (Elabscience, Wuhan, China) following the manufacturer's instructions. The coefficients of variations were $10 \%$. The results were expressed in nanograms per milliliter.

\section{Analysis of TOS/TAC}

The TOS was measured using a test kit from Rel Assay Diagnostics (Gaziantep, Turkey). The intra- and inter-assay variations of the 
TOS measurements were $3.2 \%$ and $3.9 \%$, respectively. The results were expressed in micromoles of $\mathrm{H}_{2} \mathrm{O}_{2}$ per liter.

The TAC was measured using a test kit from Rel Assay Diagnostics (Gaziantep, Turkey). The intra- and inter-assay variations of the TAC measurements were $2.8 \%$ and $3.3 \%$, respectively. The results were expressed in millimoles Trolox equivalent per liter.

The OSI was determined as the TOS-to-TAC ratio, where OSI $=[(\mathrm{TOS}, \mu \mathrm{mol} / \mathrm{L}) /(\mathrm{TAS}$, $\mu \mathrm{mol} / \mathrm{L}) /(100)$.

\section{Statistical analysis}

All statistical analyses were performed using Number Cruncher Statistical System 2007 (NCSS, Utah, East Kaysville, USA). We employed Student's $t$-test for intergroup comparisons of normally distributed numerical parameters, and the Mann-Whitney $U$ test for intergroup comparisons of non-normally distributed parameters. Pearson's chi-square test and Fisher's exact test were used to compare qualitative data. Data are presented as the means \pm standard deviation (SD), percentages $(\%)$, or medians (min-max) as appropriate. A $p$ value $<0.05$ was considered to reflect statistical significance.

\section{Results}

Term infants (gestational age $\geq 37$ weeks) were included in the study, and divided into two phototherapy groups of 20 patients. There were no significant differences in gestational week, birth weight, sex, route of delivery, type of feeding, age at the moment of application, TB level before or after phototherapy, or hematocrit level at the start or termination of phototherapy between the two groups ( $p$ $>$ 0.05). However, phototherapy duration differed significantly between the groups, where Group II $(8.7 \pm 3.3 \mathrm{~h})$ received a shorter average duration of treatment than Group I $(11.4 \pm 5$ h $)(p<0.05)$ (Table I). No side effects of phototherapy were observed during either treatment.

Before commencing phototherapy, there were no significant differences $(p>0.05)$ in $8-\mathrm{OH}-$ dG level between Group I (1.75 $\pm 0.73 \mathrm{ng} /$ $\mathrm{mL})$ and Group II $(1.44 \pm 0.41 \mathrm{ng} / \mathrm{mL})$, TOS between Group I $\left(40.63 \pm 15.44 \mu \mathrm{mol} \mathrm{H}_{2} \mathrm{O}_{2} / \mathrm{L}\right)$ and Group II $\left(49.3 \pm 22.71 \mu \mathrm{mol} \mathrm{H}_{2} \mathrm{O}_{2} / \mathrm{L}\right)$, or TAC between Group I $(2.34 \pm 0.21 \mathrm{mmol}$ Trolox equiv./L) and Group II $(2.33 \pm 0.18$ mmol Trolox equiv./L) (Table II).

Similarly, after phototherapy, there were no significant differences $(p>0.05)$ in $8-\mathrm{OH}-\mathrm{dG}$ level between Group I $(1.48 \pm 0.54 \mathrm{ng} / \mathrm{mL})$ and Group II $(1.45 \pm 0.33 \mathrm{ng} / \mathrm{mL})$, TOS between

Table I. Baseline Demographic Data of the Newborns in the Study.

\begin{tabular}{lccc}
\hline Parameter & $\begin{array}{c}\text { Group I } \\
(\mathrm{n}=20)\end{array}$ & $\begin{array}{c}\text { Group II } \\
(\mathrm{n}=20)\end{array}$ & P value \\
\hline Gestational age (week) (mean $\pm \mathrm{SD})$ & $38.5 \pm 1.2$ & $38.3 \pm 0.8$ & 0.652 \\
Birth weight $(\mathrm{g})($ mean $\pm \mathrm{SD})$ & $3236 \pm 442$ & $3293 \pm 319$ & 0.643 \\
Sex $(\mathrm{F} / \mathrm{M})$ & $7 / 13$ & $10 / 10$ & 0.523 \\
Delivery method (vaginal/cesarean) & $9 / 11$ & $8 / 12$ & 1.000 \\
Age at the start of phototherapy (h) (mean $\pm \mathrm{SD})$ & $103 \pm 33$ & $102 \pm 28$ & 0.967 \\
Phototherapy duration (h) (mean $\pm \mathrm{SD})$ & $12 \pm 5$ & $9 \pm 3$ & $0.048^{*}$ \\
Serum TB at the start of phototherapy (mg/dL) (mean $\pm \mathrm{SD})$ & $18 \pm 1.8$ & $19 \pm 1.7$ & 0.094 \\
Serum TB level at the termination of phototherapy $(\mathrm{mg} / \mathrm{dL})$ & $13 \pm 1.7$ & $13 \pm 1.8$ & 0.449 \\
(mean \pm SD) & & & \\
Hematocrit at the start of phototherapy (\%) & $55 \pm 5.3$ & $55 \pm 6$ & 0.912 \\
Hematocrit at the termination of phototherapy (\%) & $56 \pm 4.9$ & $55 \pm 5.4$ & 0.408 \\
\hline
\end{tabular}

Group I: Conventional fluorescent phototherapy, Group II: High-intensity LED phototherapy, TB: Total bilirubin. $* \mathrm{P}<0.05$ 


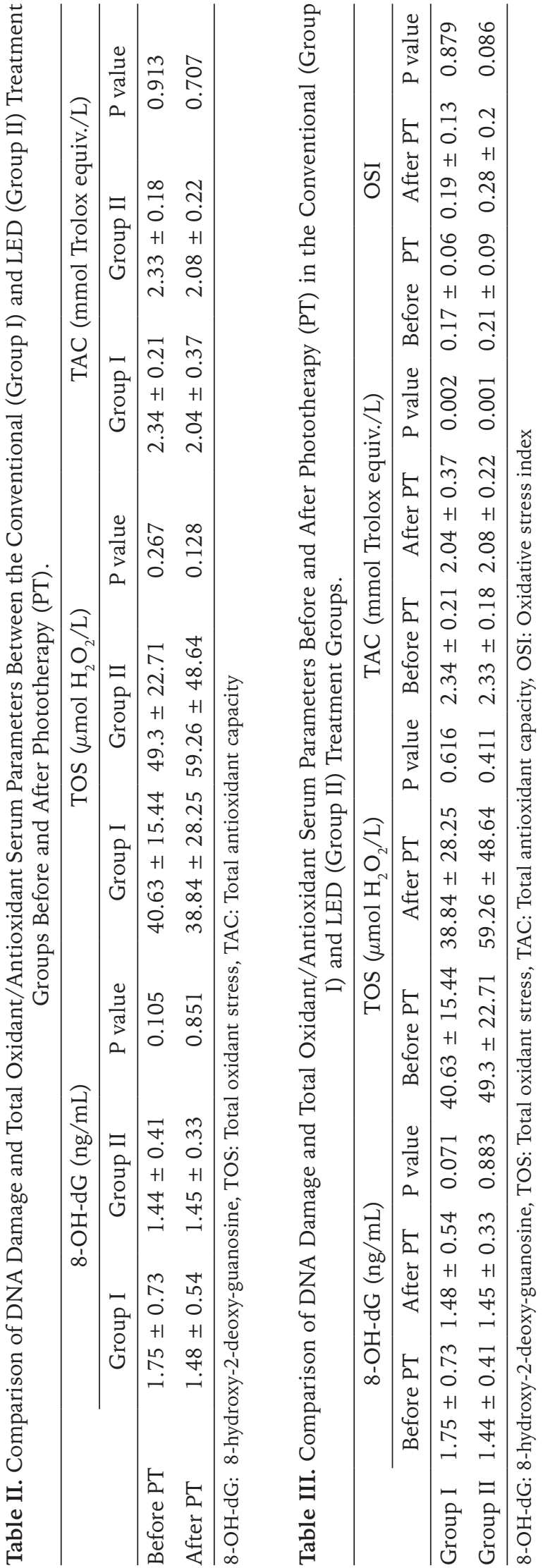

Group I $\left(38.84 \pm 28.25 \mu \mathrm{mol} \mathrm{H}_{2} \mathrm{O}_{2} / \mathrm{L}\right)$ and Group II $\left(59.26 \pm 48.64 \mu \mathrm{mol} \mathrm{H}_{2} \mathrm{O}_{2} / \mathrm{L}\right)$, or TAC between Group I $(2.04 \pm 0.37 \mathrm{mmol}$ Trolox equiv./L) and Group II (2.08 \pm 0.22 mmol Trolox equiv./L) (Table II).

In Group II, the TOS increased from $49.3 \pm$ $22.71 \mu \mathrm{mol} \mathrm{H}_{2} \mathrm{O}_{2} / \mathrm{L}$ before to $59.26 \pm 48.64$ $\mu$ mol $\mathrm{H}_{2} \mathrm{O}_{2} / \mathrm{L}$ after phototherapy, albeit nonsignificantly $(p>0.05)$. Meanwhile, the TAC decreased significantly after phototherapy in both Group I (before: $2.34 \pm 0.21 \mathrm{mmol}$ Trolox equiv./L; after: $2.04 \pm 0.37 \mathrm{mmol}$ Trolox equiv./L; $p=0.002$ ) and Group II (before: $2.33 \pm 0.18 \mathrm{mmol}$ Trolox equiv./L; after: $2.08 \pm 0.22 \mathrm{mmol}$ Trolox equiv. $/ \mathrm{L} ; p=$ 0.001) (Table III).

\section{Discussion}

The results of this study revealed that neither conventional (Group I) nor intensive (Group II) phototherapies influenced DNA damage or oxidative stress in jaundiced newborns over the course of treatment. This was in contrast to many studies that have indicated DNA damage arising from phototherapy. For instance, Goyanes-Villaescusa et al. ${ }^{18}$ suggested that phototherapy increased the sister chromatid exchange (SCE) frequency. Wu et al. ${ }^{19}$ exposed $G_{0}$ lymphocytes isolated from newborns to blue or green phototherapy light and found that both colors, but especially blue light, induced SCE. Meanwhile, Tatli et al. ${ }^{11}$ showed that conventional phototherapy increased DNA damage in newborns using the alkaline Comet assay. In addition, Karadag et al. ${ }^{20}$ suggested that both intensive and conventional therapies induced an increase in SCE frequency in the T lymphocytes of newborns over the course of treatment. Similarly, Ramy et al. ${ }^{14}$ found that conventional and intensive phototherapy treatments increased DNA damage in a duration-dependent manner using the Comet assay. Mohamed and Niazy ${ }^{21}$ showed that DNA damage scores and SCE frequencies were higher in infants exposed to intensive phototherapy than in those treated with conventional phototherapy. Moreover, Yahia et al. ${ }^{13}$ demonstrated phototherapy-induced DNA damage and apoptosis in peripheral blood lymphocytes of full-term infants. 
However, in vivo follow-up studies of full-term neonates from birth to childhood ${ }^{22,23}$ and an in vitro study using normal human fibroblasts exposed to visible light demonstrated that phototherapy had non-permanent adverse effects on DNA, ${ }^{24}$ despite the striking DNA damage effect of phototherapy.

In contrast to these studies, and supporting our findings, Schwartz et al. ${ }^{25}$ reported no difference in terms of SCE frequency between newborns who underwent phototherapy and the control group; another study observed similar results. ${ }^{26}$ Finally, Karakükcü et al. ${ }^{27}$ demonstrated that phototherapy did not cause an increase in DNA oxidation or induce genotoxic effects.

Interestingly, in the present study, although neither conventional nor LED phototherapies influenced the TOS or OSI in jaundiced newborns, the TAC significantly decreased after phototherapy in both groups. Many studies have evaluated the effects of phototherapy on oxidant/antioxidant status. For example, Aycicek et al. ${ }^{10}$ showed that conventional phototherapy increased serum lipid hydroperoxide levels and negatively impacted the oxidant/antioxidant defense system in hyperbilirubinemic full-term infants; however, they reported that the TAC was not significantly altered by phototherapy. By contrast, Atici et al. ${ }^{28}$ showed that the TAC was significantly higher in the patient group before conventional phototherapy compared with the control group, and significantly decreased after phototherapy in the patient group. Meanwhile, Kale et al. ${ }^{12}$ found that both conventional phototherapy with blue fluorescent lights and intensive LED phototherapy significantly decreased serum TAC and increased OSI values. Allam et al. ${ }^{15}$ demonstrated that both conventional and LED phototherapy resulted in increased OSI values; however, alteration of antioxidant/oxidant parameters was more pronounced after conventional than after LED phototherapy. Another study reported increased oxidative stress following conventional phototherapy, but found no significant change following LED phototherapy. ${ }^{29}$ Finally, Akisu et al. ${ }^{30,31}$ found no significant changes in malondialdehyde or antioxidant parameter values after phototherapy.
Importantly, these studies were not standardized in terms of the number of patients included in the study population, gestational ages and birth weights of patients, sampling time, relationship between sampling time and phototherapy, phototherapy device, or phototherapy duration. Such methodological differences could explain the conflicting results.

Under physiological conditions, uric acid, vitamin $C$, and sulfhydryl groups are decreased in the newborn plasma, whereas bilirubin and vitamin $\mathrm{E}$ levels are increased to maintain the antioxidant balance. ${ }^{32}$ In this study, serum TAC was significantly lower after than before phototherapy. This decrease was attributed to the rapid decrease in hyperbilirubinemia by phototherapy and to the inadequacy of the compensatory system given that bilirubin constitutes the majority of the antioxidant system in the newborn period.

In this study, the duration of LED phototherapy was shorter than conventional phototherapy. Some studies have reported different findings with respect to the duration of phototherapy. ${ }^{20,33}$ This finding was likely to have been caused by the higher light irradiation intensity of the LED phototherapy system, resulting in more efficient treatment of neonatal jaundice.

It should be noted that this study was limited in terms of the small sample size; therefore, future studies of the effects of phototherapy on DNA damage and oxidant/antioxidant status during the treatment of neonatal jaundice in a larger sample size are warranted.

In conclusion, our findings indicate that conventional and intensive phototherapies do not cause an increase in DNA damage and oxidative stress, and are safe, preferable treatments for neonatal jaundice.

\section{REFERENCES}

1. Maisels MJ, Gifford K, Antle CE, Leib GR. Jaundice in the healthy newborn infant: a new approach to an old problem. Pediatrics 1988; 81: 505-511.

2. Kaplan M, Hammerman C. Understanding severe hyperbilirubinemia and preventing kernicterus: adjuncts in the interpretation of neonatal serum bilirubin. Clin Chim Acta 2005; 356: 9-21. 
3. Maisels MJ, McDonagh AF. Phototherapy for neonatal jaundice. N Engl J Med 2008; 358: 920-928.

4. Lightner DA, McDonagh AF. Molecular mechanisms of phototherapy for neonatal jaundice. Acc Chem Res 1984; 17: 417-424.

5. Porter ML, Dennis BL. Hyperbilirubinemia in the term newborn. Am Fam Physician 2002; 65: 599-606.

6. Vreman HJ, Wong RJ, Stevenson DK. Phototherapy: current methods and future directions. Semin Perinatol 2004; 28: 326-333.

7. Dani C, Martelli E, Reali MF, Bertini G, Panin G, Rubaltelli F. Fiberoptic and conventional phototherapy effects on the skin of premature infants. J Pediatr 2001; 138: 438-440.

8. Maisels MJ. Phototherpy-tradiotional and nontradiotinal. J Perinatol 2001; 21(Suppl 1): S93-S97.

9. Gathwala G, Sharma S. Oxidative stress, phototherapy and the neonate. Indian J Pediatr 2000; 67: 805-808.

10. Aycicek A, Erel O. Total oxidant/antioxidant status in jaundiced newborns before and after phototherapy. J Pediatr (Rio J) 2007; 83: 319-322.

11. Tatli MM, Minnet C, Kocyigit A, Karadag A. Phototherapy increases DNA damage in lymphocytes of hyperbilirubinemic neonates. Mutat Res 2008; 654: 93-95.

12. Kale Y, Aydemir O, Celik U, et al. Effects of phototherapy using different light sources on oxidant and antioxidant status of neonates with jaundice. Early Hum Dev 2013; 89: 957-960.

13. Yahia S, Shabaan AE, Gouida M, et al. Influence of hyperbilirubinemia and phototherapy on markers of genotoxicity and apoptosis in full-term infants. Eur J Pediatr 2015; 174: 459-464.

14. Ramy N, Ghany EA, Alsharany W, et al. Jaundice, phototherapy and DNA damage in full-term neonates J Perinatol 2016; 36: 132-136.

15. Allam A, Ravikiran SR, Baliga BS, Bhat K, Joseph N. Effect of conventional and LED phototherapy on the antioxidant-oxidant status in preterm neonates with jaundice. Indian Pediatr 2017; 54: 644-646.

16. Perrone S, Tataranno ML, Stazzoni G, Buonocore G. Biomarkers of oxidative stress in fetal and neonatal diseases. J Matern Fetal Neonatal Med 2012; 25: $2575-2578$

17. American Academy of Pediatrics Subcommittee on Hyperbilirubinemia. Management of hyperbilirubinemia in the newborn infant 35 or more weeks of gestation. Pediatrics 2004; 114: 297-316.
18. Goyanes-Villaescusa VJ, Ugarte M, Vazquez A Sister chromatid exchange in babies treated by phototherapy. Lancet 1977; 2: 1084-1085.

19. Wu FY, Iijima K, Takiguchi D, Nishida A, Higurashi M. Effect of phototherapy on sister-chromatid exchange in infants with Down syndrome. Mutat Res 1992; 283: 65-67.

20. Karadag A, Yesilyurt A, Unal S, et al. A chromosomaleffect study of intensive phototherapy versus conventional phototherapy in newborns with jaundice. Mutat Res 2009; 676: 17-20.

21. Mohamed WW, Niazy WH. Genotoxic effect of phototherapy in term newborn infants with hyperbilirubinemia. J Neonatal Perinatal Med 2012; 5: $381-387$.

22. Kahveci H, Dogan H, Karaman A, Caner I, Tastekin A, Ikbal M. Phototherapy causes a transient DNA damage in jaundiced newborns. Drug Chem Toxicol 2013; 36: 88-92.

23. Tsai FJ, Tsai $\mathrm{CH}$, Peng CT, Wang TR. Sister chromatid exchange in Chinese newborn infants treated with phototherapy for more than five days. Zhonghua Min Guo Xiao Er Ke Yi Xue Hui Za Zhi 1998; 39: 327-329.

24. Rosenstein BS, Ducore JM, Cummings SW. The mechanism of bilirubin-photosensitized DNA strand breakage in human cells exposed to phototherapy light. Mutat Res 1983; 112: 397-406.

25. Schwartz AL, Cole FS, Fiedorek F, et al. Effect of phototherapy on sister chromatid exchange in premature infants. Lancet 1978; 2: 157-158.

26. Hatcher NH, Risemberg HM, Powers MM, Hook EB. Sister-chromatid exchange and phototherapy. Mutat Res 1979; 60: 401-403.

27. Karakukcu C, Ustdal M, Ozturk A, Baskol G, Saraymen R. Assessment of DNA damage and plasma catalase activity in healthy term hyperbilirubinemic infants receiving phototherapy. Mutat Res 2009; 680: $12-16$.

28. Atici A, Bozkurt A, Mutlu N, Eskandari HG, Turhan AH. Oxidative stress under phototherapy. Turkiye Klinikleri J Pediatr 2009; 18: 259-263.

29. Demirel G, Uras N, Celik IH, et al. Comparison of total oxidant/antioxidant status in unconjugated hyperbilirubinemia of newborn before and after conventional and LED phototherapy: A prospective randomized controlled trial. Clin Invest Med 2010; 33: E335-E341.

30. Akisu M, Coker C, Tuzun S, Yilmaz D, Kültürsay N. Serum malondialdehyde levels in preterm and fullterm infants undergoing phototherapy. Acta Pediatr 1998; 87: 605-606. 
31. Akisu M, Yilmaz D, Tüzün $S$, Kültürsay $\mathrm{N}$. Antioxidant defense systems in newborns undergoing phototherapy. Indian J Pediatr 1999; 66: 651-655.

32. Kiely M, Morrissey PA, Cogan PF, Kearney PJ. Low molecular weight plasma antioxidants and lipid peroxidation in maternal and cord blood. Eur J Clin Nutr 1999; 53: 861-864.
33. Seidman DS, Moise J, Ergaz Z, et al. A prospective randomized controlled study of phototherapy using blue and blue-green light- emitting devices, and conventional halogen-quartz phototherapy. J Perinatol 2003; 23: 123-127. 